appear that a porcine heterograft prosthesis with additional anticoagulation would be beneficial. However, the toxic effects of eosinophilic granules on the xenograft remain to be evaluated. At autopsy in one such patient (Harley and colleagues ${ }^{2}$ ), although there were no mural thrombi, small thrombi were present on the bioprostheses despite treatment with warfarin.

Review of the literature ${ }^{4}$ further suggests that the exacerbations of symptoms in these patients, as in ours, should be treated with prednisolone $1 \mathrm{mg} / \mathrm{kg}$ and hydroxy urea $500 \mathrm{mg}$ daily. Once the endocarditis is under control and remission of systemic symptoms has occurred, operation should be planned for relief of cardiac symptoms.

\section{REFERENCES}

1. Chusid MJ, Dale DC, West BC, et al. The hypereosinophilic syndrome: analysis of fourteen cases with review of literature. Medicine 1975;54:1-27.

2. Harley JB, McIntosh CL, Kirklin JW, et al. Atrioventricular valve replacement in the idiopathic hypereosinophilic syndrome. Am J Med 1982;73:77-81.

3. Davies J, Sapsford R, Brooksby I, et al. Successful surgical treatment of two patients with eosinophilic endomyocardial disease. Br Heart J 1981;46:438-45.

4. Felice PV, Sawicki J, Anto J. Endomyocardial disease and eosinophilia. Angiology 1993;44:869-74.

\title{
A DEHYDROMONOCROTALINE-INDUCED PULMONARY HYPERTENSION MODEL IN THE BEAGLE
}

\author{
Morihito Okada, MD, Chojiro Yamashita, MD, Masayoshi Okada, MD, and Kenji Okada, MD, Kobe, Japan
}

Pulmonary hypertension ( $\mathrm{PH})$ is a poorly understood disease process for which no adequate therapy exists. Trials to gain a better understanding of $\mathrm{PH}$ have been hindered by the lack of relevant animal models. Although monocrotaline and hypoxia have both been used to generate $\mathrm{PH}$ in rats, ${ }^{1,2}$ rats are too small to allow hemodynamics to be evaluated accurately. We therefore tried to establish a model of $\mathrm{PH}$ in a larger animal, the beagle. However, a homogeneous model could not be produced in dogs by the administration of monocrotaline or by the long-term exposure to hypoxia. It is considered that monocrotaline is activated to a reactive metabolite in the liver and is then transported by red blood cells to the lung, where it initiates endothelial injury. The difference regarding the effect of monocrotaline on the lung between a rat and a dog, which might be due to the hepatic metabolic system, encouraged us to examine the reactive hepatic metabolites. The purpose of this study was to evaluate the cardiopulmonary hemodynamic alterations that developed in beagles after the direct administration of dehydromonocrotaline (DMCT), a putative toxic metabolite of monocrotaline, which was made in vitro.

Twenty purebred beagles with a mean age of 3 months and weighing 4 to $6 \mathrm{~kg}$ were used for the study. DMCT was prepared as described by Mattocks ${ }^{3}$ and was dissolved in dimethylformamide just before injection. After the baseline hemodynamics were measured, a single injection of DMCT, $1.5 \mathrm{mg} / \mathrm{kg}(n=7), 3 \mathrm{mg} / \mathrm{kg}(n=10)$, or 4.5

From the Department of Surgery, Division II, Kobe University School of Medicine, Kobe, Japan.

J THORAC CARDIOVASC SURG 1995;110:546-7

Copyright (C) 1995 by Mosby-Year Book, Inc.

$0022-5223 / 95 \$ 3.00+0 \quad \mathbf{1 2 / 5 4 / 6 2 4 6 1}$ $\mathrm{mg} / \mathrm{kg}(n=3)$, was performed. Hemodynamic data and blood samples were obtained 8 weeks after injection. For each hemodynamic measurement, the beagles were anesthetized with sodium pentobarbital $(25 \mathrm{mg} / \mathrm{kg}$ intravenously) and permitted to breathe spontaneously. Under stable conditions, a Swan-Ganz catheter (Baxter Healthcare Corporation, Edwards Div., Santa Ana, Calif.) was placed from the femoral vein to the pulmonary artery for measurement of pressure in the right side of the heart, and another catheter was placed in the femoral artery for measurement of systemic pressure. So that the weight ratio of the right to left ventricle could be calculated, the interventricular septum was included with the left ventricle. Portions of each lung and right ventricle were fixed, cut, and stained for histologic study. All animals received humane care in compliance with the "Principles of Laboratory Animal Care" formulated by the National Society for Medical Research and the "Guide for the Care and Use of Laboratory Animals" prepared by the Institute of Laboratory Animal Resources and published by the National Institutes of Health (NIH Publication No. 86-23, revised 1985). Data and variables were compared by multiple analysis of variance to determine the effect of study groups and time points. Differences were considered significant at $p<0.05$ by the Scheffe $F$ test. All data in the text are presented as the mean \pm the standard deviation.

Because two beagles receiving $3 \mathrm{mg} / \mathrm{kg}$ injections and all receiving $4.5 \mathrm{mg} / \mathrm{kg}$ injections died of acute pulmonary edema within the first week of the DMCT administration, seven beagles receiving $1.5 \mathrm{mg} / \mathrm{kg}$ injections and eight receiving 4.5 injections were available for analysis. No significant differences were noted between the groups with respect to hemodynamic variables at baseline. The systolic pulmonary arterial pressure, mean pulmonary arterial pressure, and pulmonary vascular resistance in beagles 
receiving $3 \mathrm{mg} / \mathrm{kg}$ injections significantly increased for 8 weeks from $21 \pm 2$ to $56 \pm 9 \mathrm{~mm} \mathrm{Hg}, 12 \pm 2$ to $37 \pm 6 \mathrm{~mm}$ $\mathrm{Hg}$, and $344 \pm 130$ to $2254 \pm 425$ dyne $\cdot \mathrm{sec} \cdot \mathrm{cm}^{-5}$, respectively. The cardiac output was significantly reduced from $1.6 \pm 0.3$ to $1.0 \pm 0.2 \mathrm{~L} / \mathrm{min}$ in beagles receiving 3 $\mathrm{mg} / \mathrm{kg}$ injections. However, these changes in beagles receiving $1.5 \mathrm{mg} / \mathrm{kg}$ injections were not so marked. The heart rate, mean arterial pressure, right atrial pressure, and pulmonary capillary wedge pressure remained relatively stable throughout the study period. The oxygen saturation significantly decreased from $99 \% \pm 1 \%$ to $94 \% \pm 3 \%$ in beagles receiving $3 \mathrm{mg} / \mathrm{kg}$ injections. Gross pathologic evaluation revealed that the right ventricles were enlarged and the weight ratio of the right to left ventricle increased from $0.38 \pm 0.07$ to $0.50 \pm 0.07$ in beagles receiving $3 \mathrm{mg} / \mathrm{kg}$ injections. On histologic study, the right ventricular sections showed moderate myocyte hypertrophy and the thickness of the media in small pulmonary arteries was increased. Our data suggested that beagles treated with a $3.0 \mathrm{mg} / \mathrm{kg}$ injection of DMCT produced a unique, relatively noninvasive model of $\mathrm{PH}$. There was a close correlation between the dose of DMCT and the severity of induced disease.

Heart-lung transplantation has become a routine procedure in the treatment of patients with end-stage $\mathrm{PH}$. Recently, because of serious shortages of heart-lung blocks, single lung transplantation has been promoted as a possible alternative to heart-lung transplantation for endstage pulmonary vascular disease of either primary or secondary causes. ${ }^{4,5}$ Despite clinical success with single lung transplants for $\mathrm{PH}$, many problems remain to be solved. An interesting question is whether combined heart-lung, isolated single, or bilateral lung transplantation would be preferable for the treatment of patients with
PH. In clinical lung transplantation for end-stage pulmonary vascular disease, cardiopulmonary bypass is necessary during the procedure. Although lung transplantation in rats with $\mathrm{PH}$ has been investigated, rats are too small to be subjected to such circulatory assistance. For this reason a design for a new experimental model to induce $\mathrm{PH}$ in a larger animal is of vital importance for transplantation basal study. Furthermore, these relatively large animal models, in which hemodynamics can be measured accurately, are considered to be valuable for further studies not only on transplantation but also on pharmacology. We have now used this model to study relevant physiology and pathophysiology in $\mathrm{PH}$ and right ventricular function.

\section{REFERENCES}

1. Hayashi Y, Hussa JF, Lalich JJ. Cor pulmonale in rats. Lab Invest 1967;16:875-81.

2. Rabinovitch M, Gamble W, Nadas AS, Miettinen OS, Reid L. Rat pulmonary circulation after chronic hypoxia: hemodynamic and structural features. Am J Physiol 1979;236:H818-27.

3. Mattocks AR. Dihydropyrrolizidine derivatives from unsaturated pyrrolizidine alkaloids. J Chem Soc 1969; 8:1155-62.

4. Levine SM, Gibbons WJ, Bryan CL, et al. Single lung transplantation for primary pulmonary hypertension. Chest 1990;98:1107-15.

5. Pasque MK, Kaiser LR, Dresler CM, Trulock E, Triantafillou AN, Cooper JD. Single lung transplantation for pulmonary hypertension. J ThORAC CARDIoVASC SURG 1992;103:475-82.

\title{
A TECHNIQUE TO MINIMIZE AIR LEAKAGE AFTER EXCISION OF EMPHYSEMATOUS BULLA OF THE LUNGS
}

\author{
Iwao Takanami, MD, Yasuki Yamamoto, MD, Tatsuya Yamamoto, MD, and Susumu Kodaira, MD, Tokyo, Japan
}

If pulmonary plication is done to treat an emphysematous bulla, pulmonary fistulae are sometimes formed and persist for long periods. ${ }^{1}$ We recently established a technique to easily reduce postoperative air leakage with the use of bioabsorbable polyglactin 910 (Vicryl mesh; John-

From the First Department of Surgery, Teikyo University of School of Medicine, 2-11-1 Kaga Itabashi-Ku, Tokyo 173, Japan.

J THORAC CARDIOvasc SuRg 1995;110:547-8

Copyright (C) 1995 by Mosby-Year Book, Inc.

$0022-5223 / 95 \$ 3.00+0 \quad \mathbf{1 2 / 5 4 / 6 2 1 0 3}$ son \& Johnson Cardiovascular, King of Prussia, Pa.), a GIA $8 \mathrm{~cm}$ linear stapling device (United States Surgical Corporation, Auto Suture Company Division, Norwalk, Conn.), and fibrin glue (Bolheal; Teijin, Inc., Tokyo, Japan).

Several strips of absorbable polyglactin $910(1 \mathrm{~cm}$ wide and $8 \mathrm{~cm}$ long) were prepared. One of these strips was bonded by fibrin glue onto both sides of the GIA linear stapling device (the cartridge side and the front side) (Fig. 1). The bulla was lifted by pulmonary forceps until it had a tentlike appearance. The stapling device to which strips of polyglactin 910 had been bonded was applied across the pulmonary base that was to be resected. The stapler was then used to resect the target tissue. In cases in which the 